\title{
BLOCK LEVEL PLANNING OF CROPS USING GIS
}

\author{
K. Mahendran*, A. R. Santhakumar**, R. Balasubramanian* \\ *Gandhigram Rural University, Gandhigram-624302. \\ **Indian Institute of Technology Madras, Chennai -600 025. \\ mahendran_gri@rediffmail.com
}

\begin{abstract}
The geographical information system (GIS) is a computer-based technology that describes, stores, manipulates and analyzes information spatially and produces output in the form of maps and data tables which could be used for precise planning and decision making in agricultural development process too. Land, soil and land use pattern are the most viable factors to decide the agricultural yield. The southern part of Tamil Nadu, India mainly depends on rain and ground water potential for agriculture. The soil information on Athoor block of Dindigul District related to the agricultural sector is prepared from the soil survey data. The digital data sources are created using GIS. The administrative boundary was overlaid with soil data for the purpose of agricultural planning at the block level. The suggested cropping pattern will help the farmers to improve the yields.
\end{abstract}

\section{INTRODUCTION}

India is an agro-based country and its growth and the stability of rural economy is vitally influenced by agricultural economy. Unfortunately, most of the habitants of the villages are small-scale farmers. The accelerated growth of population has fueled the demand for agricultural commodities and often there is a mismatch between the demand and supply. So, it is essential to evolve a viable and optimized working pattern to increase the agricultural yields. It is essential to study the local cropping patterns with respect to the soil suitability at microlevel. In this context, design of block level planning of crops is expected to provide better comprehensive and integrated insight into sustained agricultural development and an associated rural development.

Remote sensing and GIS has added new dimensions for planning, development and management of advanced eco-systems which have a direct impact on cropping. The cluster of remote sensed data facilitates the systematic analysis of time-stamped patterns and its features on earth in a local and global perspective. Such data loudly pronounce the link between the localized ecological results at regional level and international conservation and management of biological diversity.

Arun et al. (2001) has stressed the importance of village wise data at the microlevel which helps in understanding of local problems, culture and socioeconomic traits. Also, these data are important in planning in complementary areas like health and rural sanitation education, social awakening and awareness, animal husbandry, irrigation and land reclamation. A comprehensive integrated resource management focusing on the optimal utilization, multiple uses of natural resources has been advocated for 
sustainable development by Devender (1996). Natural resources such as vegetation, water, and soil play a crucial role in habitat development.

Received 2/12/2009 accepted 21/6/2010

These terrain features determine the selection of appropriate land use pattern, which in a way reflect the cultural, social and economical conditions (Vink, 1975). GIS has grown as a powerful tool for collecting, storing and retrieval of data. It transforms and delivers the real-world spatial data (Burrough, 1998). Jaykumar (2003) has studied the land use / land cover mapping and change detection and suggested the land improvement techniques so as to improve the economy of the populace.

\section{MATERIALS AND METHODS}

Tamil Nadu is one of the southern states of India, having thirty districts. Dindigul district is one among them and is located in the middle part of Tamil Nadu. This district consists of three revenue divisions, seven taluks and fourteen panchayat unions. The study area is Athoor block of this district which consists of twenty two village panchayats and three town panchayats. The area lies between the geographic co-ordinates of north latitude from $10 \square^{\circ} 14^{\prime} 50^{\prime \prime}$ to $10 \square^{\circ} 20^{\prime} 00^{\prime \prime}$ and east longitude from $77 \square^{\circ} 37^{\prime} 45^{\prime \prime}$ to $77 \square^{\circ} 46^{\prime} 00^{\prime}$ '. It lies 16 kilometers away from Dindigul, the district head quarters on its South-west. According to Census of India 2001 (the latest essential statistics available) its population amounts to 146139 . The block is surrounded by Reddiyarchatram block in North, Dindigul block in East, Nilakkottai and Batlagundu blocks in the South and Kodaikanal block in the West as shown in Figure (1).

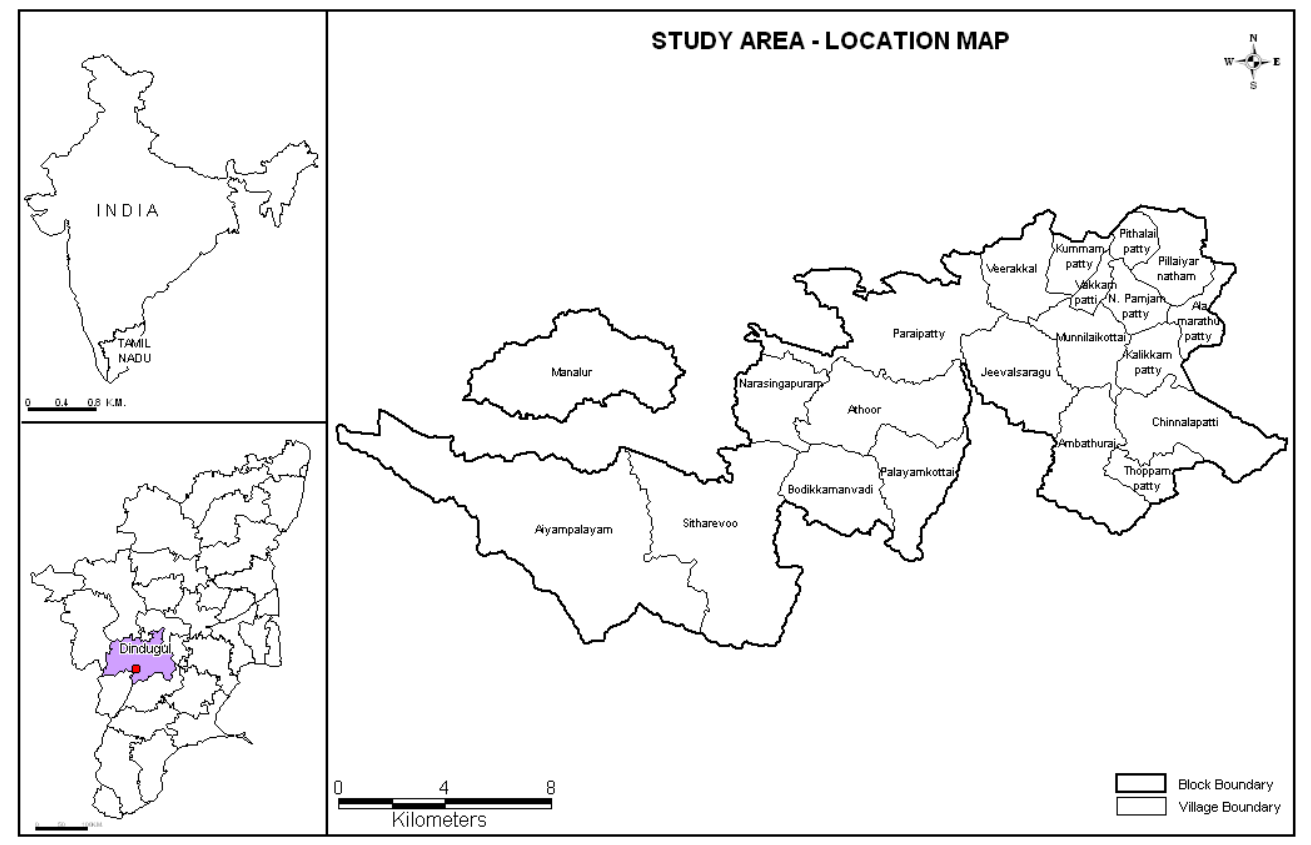

Figure (1). Study Area Location Map

The data used in the study area are comprised of remote sensing data, collateral and attribute data. The satellite data such as IRS-1C LISS III of the year 1996, IRS-1D LISS III and PAN+LISS-3 merged data of the year 2002, 
are used for the creation of land use and land cover for the year 1996 and 2002. The remote sensing data of the study area have also been verified with ground reality by using the GPS instrument. The drafting software AUTOCAD 2000, GIS software of ArcInfo and ArcView 3.2. were used in the present study. The thematic maps have been verified by making field visits and by selecting random points in the maps of the study area. The above thematic maps are then digitized through the online digitization as an input for GIS analysis. The administrative boundary is overlaid with soil data for agricultural planning at the block level.

\section{RESULTS AND DISCUSSION}

The soil series map of Dindigul taluk has been classified into different series based on its characteristics as in Table 1. Series refer to the soil having horizons similar in differentiating characteristics and developed from similar parent materials. Six such identified soil series were reported in the Survey report of Dindigul taluk (Ramu, 1984). The soil series map is shown in Figure 2.

Irugur Series (Igr): Soil under this series consists of red to dark red, moderately deep, fine loamy, non-calcareous, well-drained, medium acid to neutral soil with quartz gravels present in the solemn and on the surface. They appear to have developed over the weathered gneiss. This soil occupies the land with gentle slopes of undulating topography and susceptible to moderate to severe sheet erosion. This soil is found to be suitable for redgram, groundnut, gingelly and saamai cultivation and the natural vegetation includes neem, velvel, tamarind and palmyrah.

Somayyanur Series (Smy): This series of soil appears to be brown to dark brown, very deep, fine loamy, calcareous, and colluvial, well drained and mildly alkaline to moderately alkaline. They occupy gently sloping lands at hill bottom. They are developed from colluvial washes collected at the hill bottoms due to gravitational flow of water and wind. In this soil, millets and pulses are cultivated under rain-fed condition and under irrigation. Crops like paddy, maize, groundnut, fruit crops are predominantly cultivated. Natural vegetation which grows in this area includes acacia, palmyrah, ipomoea and calotropis. 


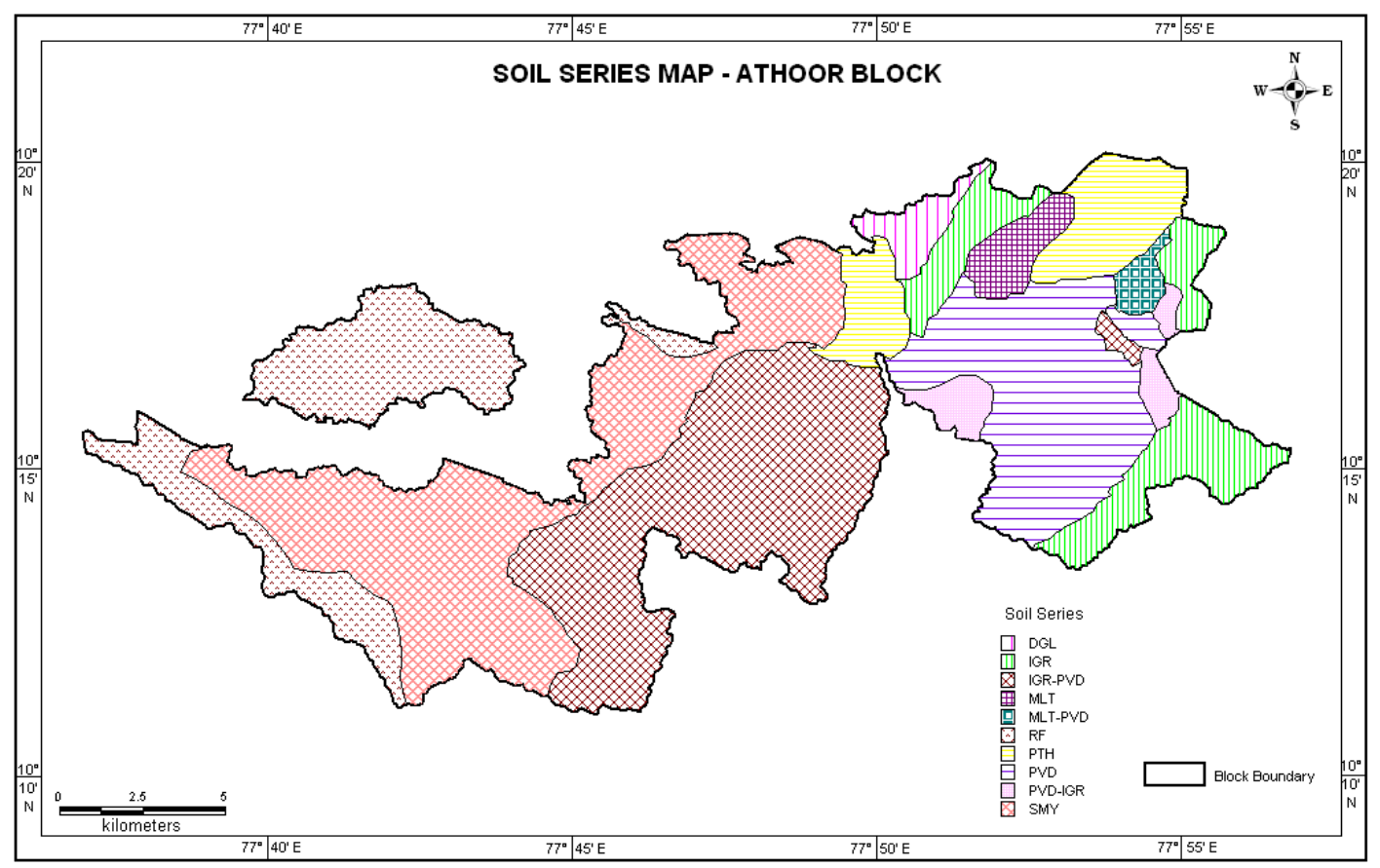

Figure (2). Soil Series Map of Athoor Block

Palathurai Series (Pth): This series is of dark brown to dark reddish brown, moderately deep-to-deep, fine, calcareous, mildly alkaline to moderately alkaline occurring on gneiss mixed lime available on very gentle slopes and are subject to moderate erosions. This soil is suitable to cultivate maize, groundnut, chillies, paddy and pulses. Natural vegetation consists of tamarind, palmyrah, acacia, banyan and neem

Table (1): Area of Soil Series in Athoor Block

\begin{tabular}{|c|c|c|c|c|}
\hline S.No. & Soil & Symbol & Area in Sq. km. & Percent \\
\hline 1. & Irgur & Igr & 22.63 & 8.74 \\
\hline 2. & Somayyanur & Smy & 66.34 & 25.61 \\
\hline 3. & Palathurai & Pth & 17.89 & 6.90 \\
\hline 4. & Palaviduthi & Pvd & 37.82 & 14.60 \\
\hline 5. & Dindigul & Dgl & 4.41 & 1.70 \\
\hline 6. & Irgur - Palaviduthi & Igr-Pvd & 59.90 & 23.13 \\
\hline 7. & Palaviduthi - Irgur & Pvd-Igr & 5.96 & 2.30 \\
\hline 8. & $\begin{array}{c}\text { Miscellaneous Land Type } \\
\text { Palaviduthi }\end{array}$ & MLT-Pvd & 2.41 & 0.93 \\
\hline 9. & Miscellaneous -Land Type & MLT & 5.27 & 2.04 \\
\hline 10. & Reserved Forest Land & RF & 36.21 & 13.98 \\
\hline
\end{tabular}

Palaviduthi Series (Pvd): This series is red to dark reddish brown, very deep, fine well drained soils with iron gravels present in the subsoil. The solemn is 23 metre deep and is the result of colluvial material transported by gravitational forces. The soil occupies the foot slopes of the hills with gentle to moderate slopes. In this soil groundnut, maize, paddy, sugarcane, horsegram, chillies and other pulses are cultivated. 
Dindigul Series (Dgl): This series is dark grey to very dark grey, very deep, fine, calcareous, moderately well-drained, moderately alkaline soils occurring on very gently sloping lands and are subjected to slight to moderate sheet erosion. Cotton, maize, raagi and other minor millets are cultivated in this series. Natural vegetation includes palmyrah, tamarind, neem, prosophis and acacia.

Miscellaneous Land Type (MLT): Besides the five soil series mentioned above, there are also soils which do not fit into any of the already well established series due to their varying soil characters. They have been mapped under miscellaneous land type. From Table (1), it is evident that irgur, somayyanur, palaviduthi, palathurai, irgur-palaviduthi and the reserved forest land form major soil series in Athoor block. The crop pattern as studied through GIS is matched with the ground reality. The statistical data available in literature shows that average rainfall is $831 \mathrm{~mm}$ per year and average relative humidity is 70 per cent. The ground reality is that ground nut, maize, paddy, sugarcane, horsegram and other pulses are cultivated in this block.

Land Use Map 1996: The major land use classes identified in the study area are agricultural crops, plantations, upland with/without scrub, habitations and water bodies. The agricultural crop area available in the study area has been classified into two types as Rabi and Khariff. The satellite imagery shows a complete red patches along the river, indicating good growth of crops especially during a season. The predominant crops available in this area are paddy and sugarcane which are cultivated sporadically. In the remaining areas, the rain-fed crops such as groundnut, raagi and other pulses are cultivated. Plantation crops such as coconut, grapes, guava, mango and plantain are also grown in the flat terrain. The important classifications are given in Table(2).

As shown in Figure (3) and Table (2), the land use map of 1996 shows that 75 percent of TGA has the potential to cultivate the crops such as paddy, maize, groundnut and sugar cane. The ground water potential in this block is on the decline. The situation calls for urgent integrated action wherein measures for optimal use of water and cultivation of crops that requires the use of less water. The situation can be effectively tackled with the appropriate technological intervention coupled with the GIS support. An integrated resource management with such strategies like crop rotation, drip irrigation may aid the agricultural production in this area. 


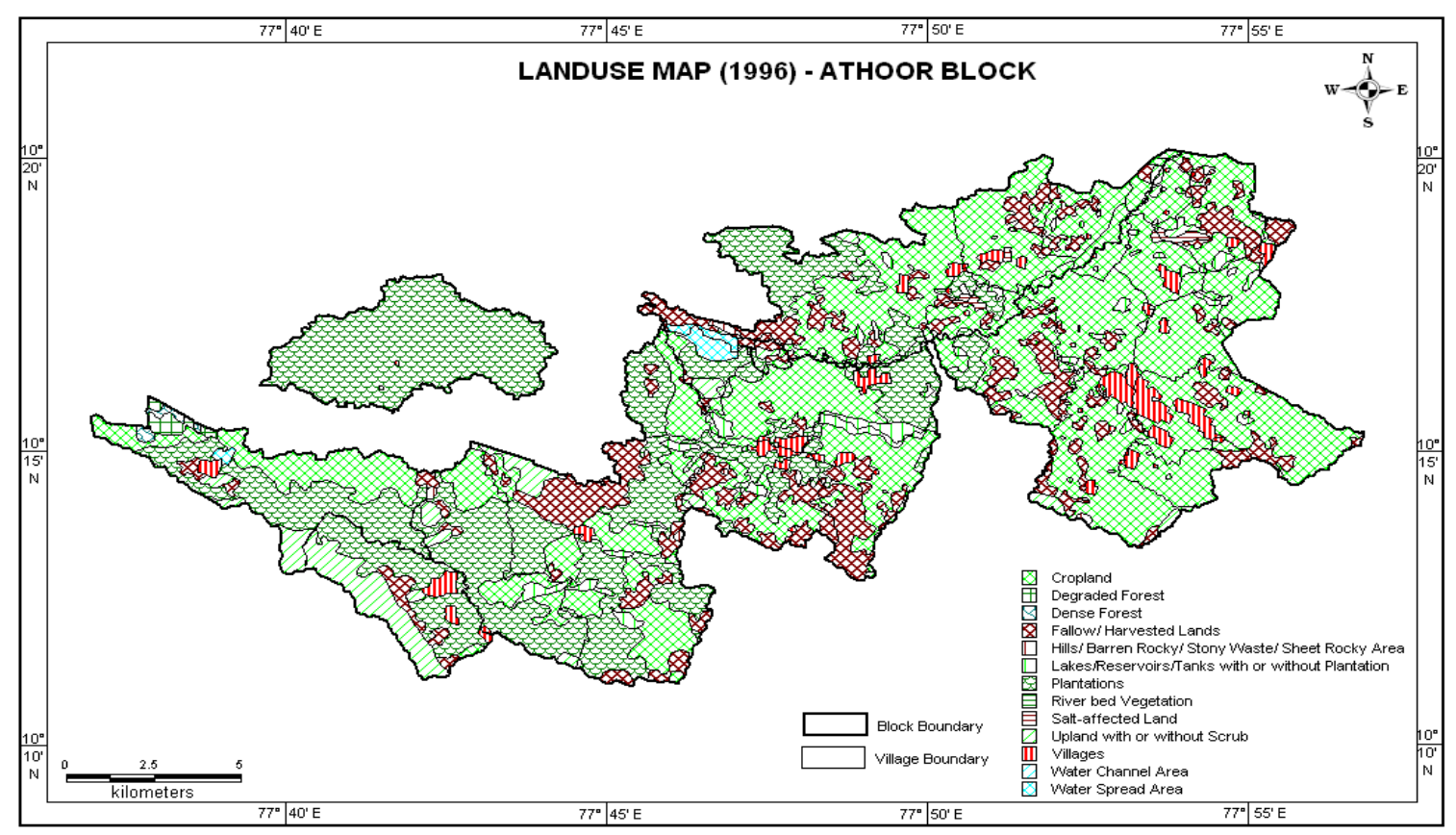

Figure (3). Land use Map (1996) of the Study Area

Table (2). Aerial Extent of Land Use of Athoor Block in 1996

\begin{tabular}{|c|c|c|c|}
\hline S.No. & Land Use Classes & Area Sq. Km & TGA per cent \\
\hline 1. & Cropland & 114.600 & 44.25 \\
\hline 2. & Fallow/ Harvested Lands & 33.809 & 13.06 \\
\hline 3. & Hills/Barren Rocky/ Stony Waste / Sheet Rocky Area & $\mathbf{0 . 5 6 1}$ & $\mathbf{0 . 2 2}$ \\
\hline 4. & Lakes/ Reservoirs/ Tanks with or without Plantation & $\mathbf{6 . 1 6 0}$ & 2.38 \\
\hline 5. & Plantations & 79.936 & 30.86 \\
\hline 6. & River bed vegetation & $\mathbf{0 . 6 4 5}$ & $\mathbf{0 . 2 5}$ \\
\hline 7. & Salt-affected Land & $\mathbf{0 . 7 8 9}$ & 0.31 \\
\hline 8. & Upland with or without Scrub & 10.740 & 4.15 \\
\hline 9. & Villages & $\mathbf{8 . 3 2 1}$ & 3.22 \\
\hline 10. & Water channel area & 0.375 & 0.14 \\
\hline 11. & Water spread area & 1.555 & 0.60 \\
\hline 12. & Degraded / Dense Forest & 1.417 & 0.55 \\
\hline & TOTAL & 258.908 & 100.00 \\
\hline
\end{tabular}

\section{CONCLUSIONS}

From previous results GIS, being an proficient tool for data analysis and management, both spatial and attribute data can be explored and exploited to devise suitable crop production strategies as it provides information not only on the characteristics of soil but also on the land use and land cover patterns. The study emphasizes the need for techno-agro interventions which may help farmers to overcome the crisis of water level depletion in this study area.

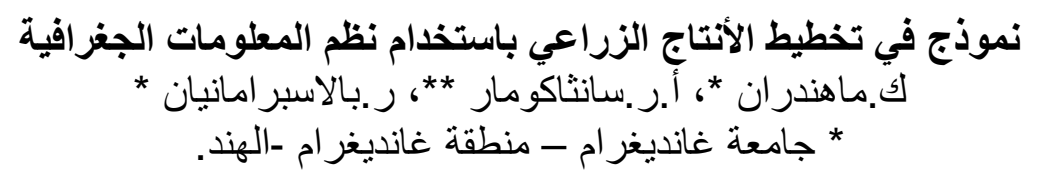




$$
\text { ** ألمعهة الهندي للتكنولوجيا ـ مدراس -الهند. }
$$

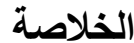

تستخدم نظم المعلومات الجغر افية تقنية الحاسوب لأجل تمثيل وخزن ومعالجة وتحليل البيانات

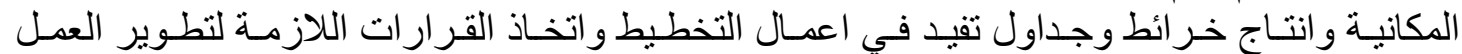

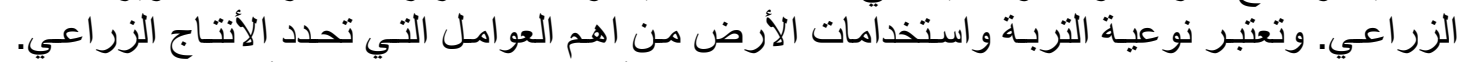

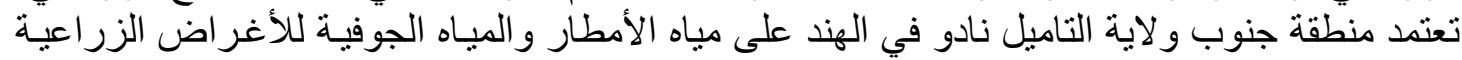

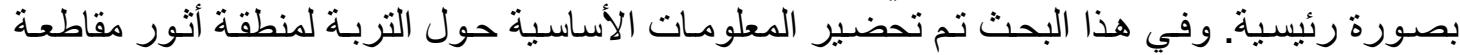

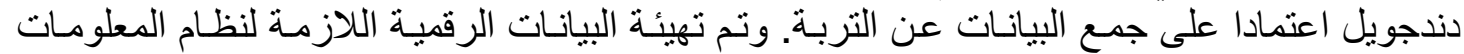

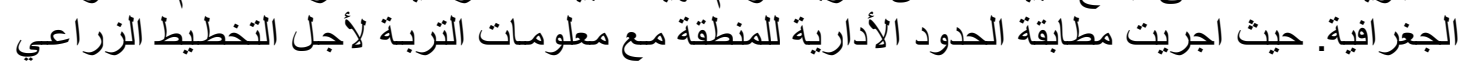
على مستوى المقاطعة. ان النموذج المقترح لتوزيع المحاصيل سبساعد المز ارعين علئ على تحسين انتاجهر

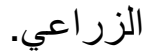

\section{REFERENCES}

Arun, C, R.K. Sexena, and D.B. Tamgadge (2001). Block level agro-regional planning integrating remote sensing and GIS technology, spatial information technology. ICORG, India, 2: 561 - 565.

Burrough, P. A. (1998). Principles of Geographical Information Systems for Land Resources, Clarendon Press, Oxford.

Devender, K. (1996). Application of remote sensing and GIS in rural planninga case study of; Indore thesil, Journal of the Indian National Cartographic Association, India. 16, 132 - 136.

Jaykumar, S. (2003). Land use and Land cover mapping change detection in part of Eastern ghats of Tamil Nadu using remote sensing and GIS. Journal of Indian Society of Remote Sensing, 31, (4). 251-260.

Ramu, S. (1984). Soil Survey Report of Dindigul Taluk, Madurai District. TamilNadu Soil Survey and Land use Organization, Coimbatore.

Vink, A. P. (1975). Land Use in Advancing Agriculture. Springer Verlag. Berlin. 